

\title{
A percepção ambiental, identidade e pertencimento dos moradores do povoado Cabeço, em Brejo Grande/SE, frente às inundações na foz do rio São Francisco
}

\section{Environmental Perceptions, Identity and Belonging of Residents in the Town Cabeço in Brejo Grande/SE in the Face of Floods at the River São Francisco's Outfall}

\author{
Sérgio Silva de ARAÚJO ${ }^{1 *}$, Antenor Oliveira AGUIAR NETTO ${ }^{1}$, Laura Jane GOMES ${ }^{1}$ \\ ${ }^{1}$ Universidade Federal de Sergipe (UFS), São Cristóvão, SE, Brasil. \\ *E-mail de contato: araujosergio2011@gmail.com
}

Artigo recebido em 7 de dezembro de 2015, versão final aceita em 27 de fevereiro de 2016.

RESUMO: A apropriação dos recursos naturais pela hidrelétrica de Xingó gerou impactos na produção de pescado e de arroz, bem como ocasionou mudanças na foz do rio São Francisco, o que levou à inundação e à extinção do Povoado Cabeço, em Brejo Grande/SE. O presente artigo objetiva analisar a percepção ambiental, a identidade e o pertencimento dos moradores deste povoado e para tanto fez uso de entrevistas semiestruturadas. Constata que, além dos aspectos físicos, degradou-se um modo de vida e essas mudanças fazem perceber a ligação simbiótica que mantêm o homem e o meio ambiente, especialmente com o rio. Essa ligação se dá a partir da compreensão de sua existência e da relação de dependência com o meio ambiente, que é intrínseca ao seu modo de produção, em função da mesma base material. Neste artigo, se deu ênfase às perdas das referências culturais e simbólicas, bem como às perdas das redes de parentesco estabelecidas naquele espaço, identificando-as no contexto das falas dos moradores, de modo que se ensaiou uma reflexão sobre as estratégias por eles criadas para dar conta da desordem instaurada em seu mundo pessoal e social, esta causada pelo impacto das mudanças ambientais que os atingiram. Dessa forma, esses moradores se recolhem às memórias do passado, seja na perspectiva individual ou na perspectiva de uma memória coletiva, presas exaustivamente ao ontem de suas vidas pela ausência de escolhas ou de poder decidir sobre seus destinos.

Palavras-chave: Barragem de Xingó; representações sociais; recursos hídricos; bacias hidrográficas; vazão regularizada.

ABSTRACT: The appropriation of natural resources by Xingó's hydroelectric power plant caused impacts in the production of fish and rice and brought changes to the river outfall, which led to flooding and extinction of Cabeço's Village in Brejo Grande/SE. This article aims to analyze the environmental perception, identity and belonging of the residents of that town, to do so techniques of semi-structured interviews were used. It shows that beyond 
physical aspects the ways of living has degraded as well, such changes make us realize the symbiotic connection that keeps men and the environment, especially with the river. This binding occurs from the comprehension of its existence and the dependency relationship with the environment, which is intrinsic to their mode of production, due to the same base material. In this article, emphasis is given to the loss of cultural and symbolic references, as well as the loss of kinship networks established in that space, identifying them in the context of the resident's speech, so that a reflection on strategies created by them to account for the disorder introduced in their personal and social world, those caused by the impact of these environmental changes that hit them. Thus, these residents recur to memories of the past, either individual perspective or the perspective of a collective memory thoroughly attached to the last of their lives by the lack of choices or to decide on their destiny.

Keywords: Dam Xingó; social representations; water resources; watersheds; regularized flow.

\section{Introdução}

O povoado Cabeço situa-se no extremo nordeste do Estado de Sergipe, em zona de planície litorânea, na foz do rio São Francisco, onde se encontra o Farol Dom Pedro II, do ano 1870, como marco denunciador da existência do povoado. A presença de navegadores europeus no local é datada de 1501. A região ocupada há 400 anos pelos franceses foi usada para o comércio de pau-brasil (Vargas, 1999) e há 150 anos se consolidou como ilha de pescadores (Sergipe, 1997).

No ano de 1987, entre Alagoas e Sergipe, a $12 \mathrm{~km}$ do município de Piranhas/AL, a $6 \mathrm{~km}$ de Canindé do São Francisco/SE e a $179 \mathrm{~km}$ da foz do rio, foi construída a barragem do Xingó, cujo reservatório ocupa uma área de $60 \mathrm{~km}^{2} \mathrm{e}$ drenagem igual a $608.722 \mathrm{~km}^{2}$. Em razão dos impactos da barragem, essa população sofreu, em alguma medida, modificações no modo de vida. Este artigo aborda a percepção ambiental, a identidade, o pertencimento e as representações sociais dos moradores do Povoado Cabeço/Brejo Grande/SE, no baixo São Francisco.

A sede municipal está localizada nas coordenadas geográficas $10^{\circ} 25^{\prime} 28^{\prime \prime}$ de latitude sul e $36^{\circ} 07^{\prime} 44^{\prime \prime}$ de longitude oeste, com altitude de 6,0 metros, encontrando-se inserida na bacia hidrográ- fica do rio São Francisco, na margem direita. Ao norte fica o município de Piaçabuçu/AL, a oeste a Ilha das Flores/SE e a sudoeste e sul limita-se com Pacatuba/SE. Ocupa uma área de 148,9 km², com 7.742 habitantes (IBGE, 2014). A economia está ligada a atividades de pesca e à produção de arroz e coco, razão porque os habitantes do Cabeço são constituídos, em grande parte, por pescadores, plantadores de arroz e catadores de coco. A Figura 1 apresenta a localização do povoado Cabeço/Brejo Grande, no Brasil, em Sergipe e na região do baixo São Francisco, onde fica a foz do rio.

A bacia hidrográfica do rio São Francisco chama atenção por ser uma região de grandes investimentos dos setores elétrico e agrícola (Jesus \& Gomes, 2012). Estes usos são responsáveis por alterações significativas em seu regime hidrológico, refletindo com maior radicalidade na região do baixo curso, promovendo assoreamento do leito, erosão das margens, redução da fauna e da flora, aumento da cunha marítima e salinização da água e do solo, aumento do espelho e redução da lâmina d'água (Fontes, 2011).

As consequências dos impactos na calha do baixo São Francisco são sentidas a partir do início das obras de Xingó, na década de 1980. A partir do ano de 1994, após a entrada em operação da primeira turbina da usina, a erosão marinha no povoado Cabeço se acelera, com perdas materiais 


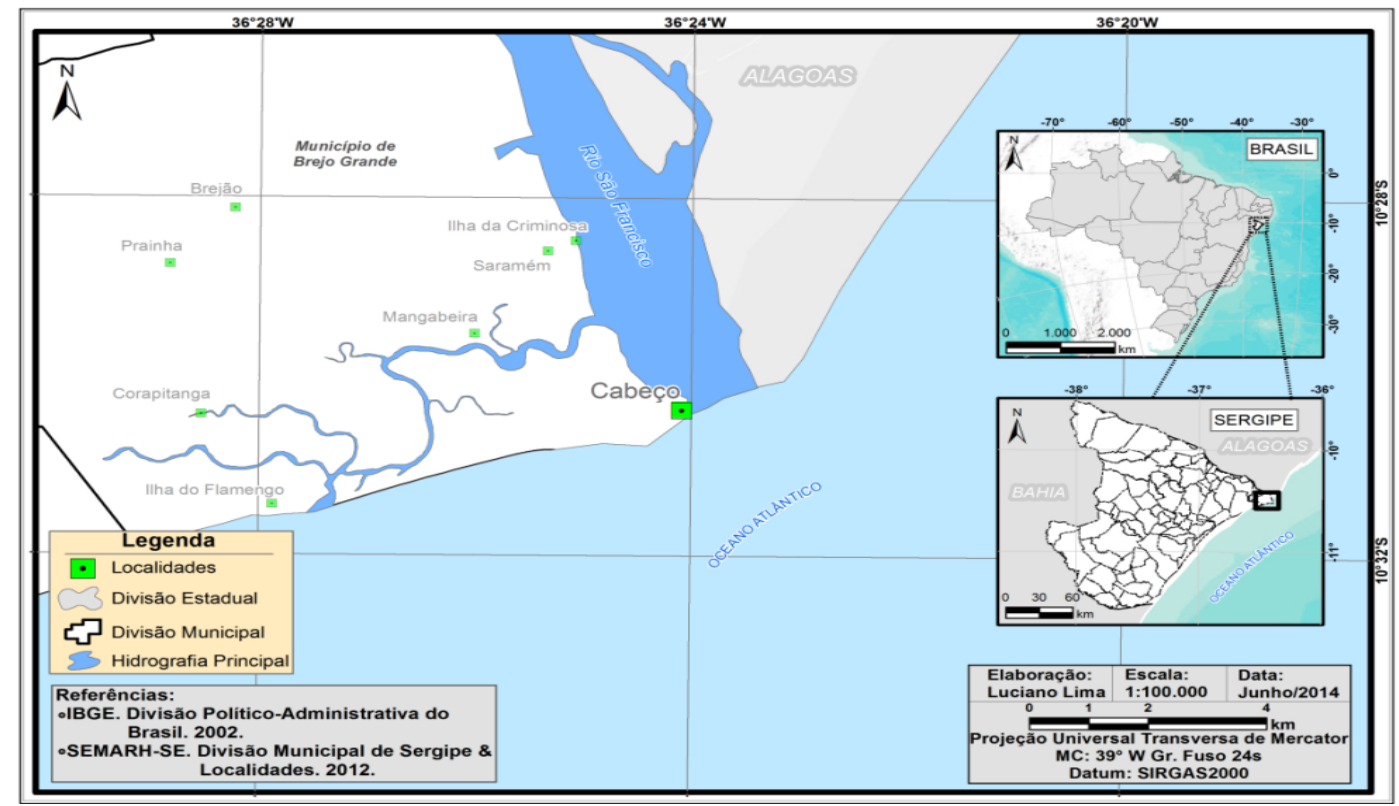

FIGURA 1- Mapa de localização do povoado Cabeço/Brejo Grande/SE.

FONTE: Araújo \& Lima (2014).

para os moradores. No ano de 2001, a invasão do povoado foi total, desterrando a comunidade, que ficou desamparada, nem mesmo sendo compensada pela CHESF (Companhia Hidrelétrica do São Francisco). No ano de 2002, o poder público municipal de Brejo Grande/SE cedeu 80 casas no povoado Saramén para alguns e outros tiveram que construir casebres de palha em área particular, para onde mudaram cerca de 40 famílias (Sergipe, 1997).

\section{Metodologia}

A metodologia foi desenvolvida por meio de entrevistas com os moradores e pescadores, que foram precedidas de visitas técnicas para contato direto com os moradores locais, em 2013. No período entre os dias 17, 21 e 28/05, 11 e 12/06, e 10/07 no ano de 2013, e nos dias 24 e 25/01/2014, foram realizadas oito viagens. Nessas viagens, também se visitou o rio São Francisco até Pontal do Peba/ Piaçabuçu/AL, a cidade de Brejo Grande, o povoado Cabeço/Brejo Grande/SE na foz do rio e outras barras. Um pescador local e um membro da ONG Canoa de Tolda descreviam as condições da foz. Fontes bibliográficas e documentais foram utilizadas para subsidiar os dados primários e consubstanciar a fundamentação teórica. Essas, por sua vez, se revestiram de grande importância na pesquisa, posto que possibilitaram detectar as mudanças na população e no meio ambiente, no tempo e no espaço.

No total dos doze entrevistados, levou-se em conta a faixa etária das pessoas, priorizando as mais idosas, na medida em que faz 14 anos que ocorreu a inundação do povoado. Registrou-se que apenas uma das entrevistas ocorreu com um jovem que à época tinha 13 anos. Os seus nomes foram ocultados e metodologicamente se utilizou o recurso de atribuir números aos entrevistados, seguindo a ordem das entrevistas. 
A análise aqui apresentada se baseia em entrevistas semiestruturadas e observações. Conforme Marconi \& Lakatos (2010, p. 190), a observação "não consiste apenas em ver e ouvir, mas também em examinar fatos ou fenômenos que se desejam estudar". Os sujeitos se colocaram livremente não somente para descrever os fatos relativos à inundação da região, como também para abordar elementos de caráter subjetivo envolvendo as vivências desses fatos. Sobre esse instrumento, Triviños (2009, p. 146) diz que “[...] ao mesmo tempo em que valoriza a presença do investigador, oferece todas as perspectivas possíveis para que o informante alcance a liberdade e a espontaneidade necessárias, enriquecendo a investigação [...]”, o que propiciou configurar a análise dos fatos que promoveram profundas alterações no modo de vida e na memória coletiva dos moradores desde que foram desterrados.

A entrevista foi o instrumento privilegiado para a obtenção de informações junto aos moradores do povoado, o que facilitou o acesso ao modo como essas pessoas percebem e interpretam a realidade, tomando a palavra como o canal de comunicação desse modo de pensar, na medida em que, segundo Bourdieu (1983), as palavras não apenas expressam como também sofrem o efeito das condições sócio-históricas da existência, razão por que servem de instrumento e material para sua comunicação.

O conteúdo apreendido, pela natureza do fato social, ou seja, pelo seu tom catastrófico, preservou a memória dos fatos vividos, o qual ganhou uma abrangência que atinge a todos, inclusive aos mais novos, permitindo absorver o máximo de informações para fundamentar as percepções que o desastre ambiental e suas consequências imprimiram naqueles moradores. Bardin (2006, p. 108) pondera que este tipo de abordagem, ainda que não produza inferências gerais, "[...] pode funcionar sobre corpus reduzidos e estabelecer categorias mais discriminadas [...]" [grifo do autor], posto que é caracterizada não pelo quantitativo da aparição do índice, mas pela sua presença.

As experiências vividas na interioridade permitem compreender como estes moradores as definem ou as explicam para si mesmos ou para o seu interlocutor, captando os significados que eles atribuem a essas experiências subjetivas. Contudo, no caso específico dos moradores do povoado, trata-se de uma experiência compartilhada, cabendo assim tomá-la como referência para ser possível extrair os significados que representam a visão de um grupo social ou os esquemas comuns de explicação das suas condições de existência. Para Bourdieu (1983), isso deve passar

[...] por todos os membros do mesmo grupo ou da mesma classe, produtos de condições objetivas idênticas que estão destinadas a exercer simultaneamente um efeito de universalização e de particularização, na medida em que elas só homogeneízam os membros de um grupo, distinguindo-os de todos os outros (Bourdieu, 1983, p. 66).

A potencialidade das palavras não surpreende desde que determina e é determinada pelas condições de existência, permitindo assim o acesso às tramas do tecido social, isto contextualizado em um determinado tempo e grupo social específico. Assim, tomou-se a linguagem como forma de conhecimento, capaz de revelar os elementos constituintes do cotidiano dos grupos sociais. A abordagem tem como suporte a análise qualitativa, visto que dá acesso às compreensões em particular de cada participante da amostra em relação à submersão do Povoado Cabeço. O mesmo encontra-se na categoria de catástrofe ambiental, em decorrência dos efeitos que imprimiu e continua imprimindo nos ecossistemas ecológicos e sociais da região. 


\section{A barragem e os moradores do Povoado Cabeço, em Brejo Grande/SE}

É presumível que a instalação de hidrelétricas cause danos ambientais, ou seja, impactos ambientais estão intrinsecamente ligados a estes empreendimentos, pois ocasionam perda de terras férteis, de fauna à montante, de fertilidades do solo, da ictiofauna, das matas ciliares à jusante, bem como impactos socioeconômicos, culturais e até danos morais. A construção de usinas hidrelétricas, ou qualquer intervenção no meio ambiente, "[...] alteram radicalmente espaços físicos regionais, seus respectivos ecossistemas terrestres e aquáticos, bem como as redes de relações sociais constituídas sobre as bases espaciais até então prevalecentes" (Acselrad \& Da Silva, 2011, p. 61).

No Brasil, desde meados do século XX, a construção de barragens tem sido o empreendimento que mais tem promovido a desterritorialização e a reterritorialização compulsória de populações (Zhouri \& Oliveira, 2005). Isto destitui as comunidades autóctones ribeirinhas de realizar a produção da sua existência, da sua base mínima de reprodução material, de seus elementos simbólicos e sociais.

A barragem alterou o regime das águas do rio e do mar, por consequência, inundou e fez desaparecer o Povoado Cabeço em Brejo Grande/SE, modificando a geomorfologia da foz do rio (Souza \& Neumann Leitão, 2000; Oliveira et al., 2003; Holanda et al., 2007; Medeiros et al., 2007; Aguiar Netto et al. 2011; Fontes, 2011; Souza et al., 2011).

O potencial hidrelétrico do rio encontra-se intensamente aproveitado, o que afeta diretamente as vazões e o carreamento de sedimentos no baixo São Francisco, causando impactos decorrentes das construções das barragens e dos respectivos lagos de reserva, desde o Alto, Submédio e Baixo curso, como as Três Marias, Sobradinho, Itaparica, Moxotó, Paulo Afonso e Xingó (Fontes, 2011).

O Cabeço, na foz do rio, teve sua geomorfologia modificada em decorrência da inundação ocorrida no ano de 2001, "onde o recuo da linha de costa levou à sua destruição". Este recuo vem se acelerando a partir do final da década de 1980 , quando a distância entre o farol e a linha de costa atinge 280m; em 1956, esse distanciamento era de 130m (Fontes, 2011, p. 63).

Para Oliveira et al. (2003), com a construção de Xingó ocorreu um novo arranjo operacional, executado pela CHESF (Companhia Hidrelétrica do São Francisco) e pelo ONS (Operador Nacional do Sistema), com regularização das vazões e o fim das cheias na região do baixo curso do rio e, por conseguinte, a diminuição significativa do material em suspensão na região, refletindo na praia do Cabeço, que sofre contínuo processo de erosão por falta de reposição de sedimentos. Souza \& Neumann Leitão (2000) evidenciam que essas condições críticas decorrentes dos processos erosivos e deposicionais de sul para norte provocaram o desvio da foz de norte para sul.

A redução da variabilidade interanual e da magnitude da vazão demonstra que o Rio São Francisco sofreu drástico decréscimo na variabilidade sazonal da vazão. Os picos de enchentes com vazões altas que ocorriam naturalmente nos primeiros meses do ano (janeiro a março) foram notavelmente reduzidos, com exceções das vazões que ultrapassaram a capacidade limite de controle das barragens, mas isso não ocorre com frequência.

Ao analisar a Figura 2, tomando-se a série histórica de vazões, entre os anos de 1977 e 2013, no município sergipano de Propriá (SE), tem-se a vazão média mensal máxima registrada pela estação fluviométrica da ANA (Agência Nacional de Águas) 49705000, Latitude 10²1'39”, Longitude 


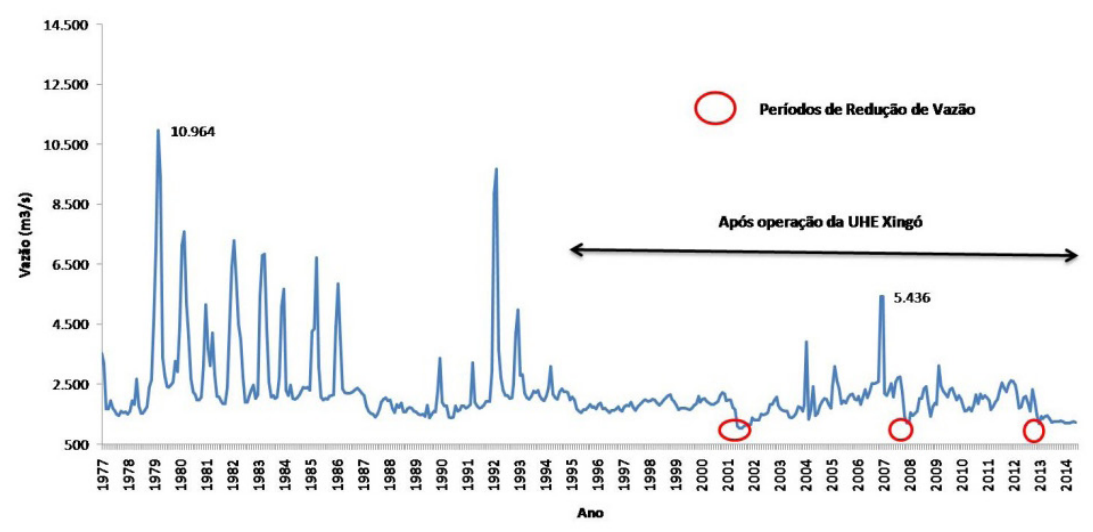

FIGURA 2 - Vazão média anual, estação fluviométrica de Propriá (1977-2014).

FONTE: ANA (2014), adaptado pelos autores.

$36^{\circ} 82^{\prime} 39$ ", de 10.964 m³/s em março de 1979 , enquanto pós-operacionalização da Usina Hidroelétrica (UHE) de Xingó esta atinge seu maior patamar, $5.436 \mathrm{~m}^{3} / \mathrm{s}$, em fevereiro de 2007, ou seja, redução de $50,42 \%$. As menores médias mensais de vazão dos últimos 37 (trinta e sete) anos foram percebidas em 2001, 2008, 2013 e 2014, períodos onde foi praticado, por resoluções da Agência Nacional de Águas (ANA) ou entidades federais responsáveis à época, o "Regime de Redução de Vazões". Em $2001,1.031 \mathrm{~m} / \mathrm{s}$; em 2008, 1.110 m³/s; e em 2013 $2014,1.167 \mathrm{~m}^{3} / \mathrm{s}$; após a conclusão da construção da Usina Hidroelétrica de Xingó, em 1994, a vazão passa a ser definitivamente regularizada.

Ainda no ano de 2001, uma seca ocasionou uma das piores reduções dos níveis de vazão de todos os tempos, ano em que se registrou uma vazão mínima de $631 \mathrm{~m}^{3} / \mathrm{s}$ no mês de agosto, na estação fluviométrica de Propriá/SE, no baixo São Francisco, segundo dados da CHESF (2013); nesse mesmo ano, também ocorreu a inundação do Povoado Cabeço/SE (Figura 3). Em outras palavras, além do controle imposto pelas barragens, há que se contabilizar as características da região, cujas condições climáticas próprias do semiárido são



FIGURA 3 - Vazões máxima e mínima registradas na estação fluviométrica de Propriá/SE no ano de 2001. FONTE: CHESF (2006), adaptado pelos autores.

responsáveis por longos períodos de seca, os quais também impõem redução nos índices de vazões.

A baixa vazão, a pouca velocidade da corrente e a diminuição de carga sólida que as barragens ao longo do seu leito têm imposto ao rio fizeram o povoado Cabeço submergir e, consequentemente, os moradores ficaram sem as condições básicas de sobrevivência, provocando o êxodo para as cidades circunvizinhas. Antes havia no local cerca de 160 casas com 400 moradores e, conforme registro da Marinha do Brasil, residiam cerca de 300 famílias. 
Estes fenômenos, juntamente com o recuo da linha de costa, revelam um dos mais graves desastres ecológicos e ambientais ocorrido no baixo curso do rio São Francisco (Sergipe, 1997).

\section{Os moradores do Povoado Cabeço e suas relações com o meio ambiente}

A análise das representações sociais se valeu principalmente da história contada pelas pessoas. Ao discorrerem sobre suas experiências, os atores tentaram explicar a sua realidade de vida, o que envolve seus modos de sobrevivência e construção da existência afetiva e social, nos mundos tangível e intangível, tomando como referência suas práticas sociais e sua relação com o meio ambiente. Este esforço cognitivo de reconfigurar suas representações, no ato mesmo em que acontece, adquire um novo status, assumindo agora o papel de elaboração de um pensamento sobre a realidade, com a possibilidade de serem estabelecidas novas conexões entre essas ideias e os fatos e de serem produzidos novos significados para esta realidade, restabelecendo assim um sentido para suas vidas.

Essa produção incessante de significados, a qual Spink (2004) associa a uma capacidade criativa, é demonstrativa da dupla face das representações sociais enquanto "[...] estruturas estruturadas e estruturas estruturantes [...]" (Spink, 2004, p. 90), isto para dizer que as representações sociais são fundadas no senso comum, daí o sentido de conhecimento prático, e ganham objetividade ao se institucionalizarem, mas são passíveis de se ressignificarem, influenciadas tanto por estímulos externos quanto internos.

As representações como processo cultural permitem a produção de significados, ao mesmo tempo em que dão sentido às identidades individual e coletiva com base em sistemas simbólicos, que “[...] tornam possível aquilo que somos e aquilo no qual podemos nos tornar" (Woodward, 2005, p. 17), bem como criando postura de sujeito e dando voz aos indivíduos. O fazer cotidiano, as regras de convivência, os rituais religiosos, símbolos e pertença ao lugar permitiram aos moradores do Cabeço a indivisibilidade do grupo até a inundação que provocou a diáspora. "[...] Uma das formas pelas quais as identidades estabelecem suas reivindicações é por meio do apelo a antecedentes históricos [...]" (Woodward, 2005, p. 11). Entretanto, as marcas do passado e as novas relações sociais, culturais e econômicas os identificam como os moradores do Cabeço. E, ainda, "essas identidades adquirem sentido por meio da linguagem e dos sistemas simbólicos pelos quais elas são representadas [...]. A construção da identidade é tanto simbólica quanto social" (Woodward, 2005, p. 8-10).

Quando se trata da percepção da realidade, esta gera uma multiplicidade de diferentes percepções (Barros-Platiau et al., 2005) e assume configurações explícitas ou implícitas, conscientes ou inconscientes (Nascimento, 2001). Estas percepções variam “[...] entre os diferentes grupos sociais, mostrando interpretação específica e particularizada dos fatores intervenientes [...]"' (Jacobi, 2006, p. 29). Não obstante, Ferrara (1993) e Santaella (2012) afirmam que a percepção é informação que gera informação, que detecta informação.

Segundo Ferrara (1993), a fruição dos usos e hábitos constrói a imagem do lugar, entretanto, a rotina do cotidiano impede a sua percepção. A superação desta rotina requer percepção ambiental gerada pela informação, que se encontra retida e codificada naqueles usos e hábitos. Nesse sentido, a percepção ambiental apreende o mundo, registra e afere significados à realidade, construindo um sistema de valores interpretado pelo indivíduo ou 
pelo social. Este sistema de valores é influenciado pelo cotidiano e por todo o ambiente que o envolve (Ferrara, 1993; Del Rio \& Oliveira, 1996).

A percepção dos moradores sobre a sua desterritorialização demonstra que entre o mundo natural e o social sobre-existe uma vinculação indissociável, apesar dos esforços acadêmicos e ideológicos contrários, no sentido de uma "purificação", conforme assim denomina Latour (2011, p. 16). $O$ autor se refere às práticas que caracterizaram a modernidade, as quais tentaram criar "duas zonas ontológicas inteiramente distintas, a dos humanos, de um lado, e a dos não humanos, de outro", entendendo que estes dois mundos colocados em separado resistem e produzem seres "híbridos de natureza e cultura" (Latour, 2011, p. 16). Práticas comuns na tradição do pensamento ocidental, seja ele filosófico, científico ou tecnológico, que tem construído uma imagem na qual a natureza e a sociedade seriam dois mundos à parte, desconectados entre si, até para justificar decisões políticas como colonização e exploração desordenada de matérias-primas.

O termo percepção utilizado nesse artigo tem como referência a teoria das representações sociais, no sentido clássico, posto que se trabalha com a percepção dos moradores do povoado Cabeço sobre os eventos que afetaram suas vidas, como a reprodução, no presente, de uma imagem ou de um conteúdo de pensamento que permaneceram preservados na memória, num esforço de representar a realidade o mais fielmente possível, por meio de sistemas de significação. E se apresentam em suas duas dimensões - a representação externa, que pode se dar através da linguagem, e a interna ou mental, que é a representação do "real" na consciência (Silva, 2005).

Quanto ao meio ambiente, este é, em sua essência, um tema vocacionado para abordagens interdisciplinares e qualquer abordagem que não leve em conta a multiplicidade e a diversidade dos aspectos envolvidos está fadada a um reducionismo que a desqualifica.

Um conceito de meio ambiente que leve em conta essa perspectiva interdisciplinar exclui a dicotomia na qual em um polo encontra-se a natureza e em outro a sociedade e o homem. Reigota (2004, p. 14) traduz meio ambiente como:

\begin{abstract}
O lugar determinado ou percebido, onde os elementos naturais e sociais estão em relações dinâmicas e em interação. Essas relações implicam processos de criação cultural e tecnológica e processos históricos e sociais de transformação do meio natural e construído.
\end{abstract}

Mas, o que se assiste em realidade é a esta polarização. O apelo é no sentido de não se misturar aquilo que se encontra no campo da natureza com os eventos políticos, as decisões governamentais, as ciências, a religião e a tecnologia, muito embora:

\footnotetext{
Um mesmo fio conecta a mais esotérica das ciências e a mais baixa política, o céu mais longínquo e uma certa usina no subúrbio de Lyon, o perigo mais global e as próximas eleições ou o próximo conselho administrativo. As proporções, as questões, as durações, os atores não são comparáveis e, no entanto, estão todos envolvidos na mesma história (Latour, 2011, p. 7).
}

As mudanças no ecossistema não passam despercebidas, uma vez que seus impactos são objetivos. Com isso, assistimos a uma corrida em direção à produção de conhecimentos, visando, dentre outros interesses, a um melhor aproveitamento dos recursos naturais.

No momento em que a população foi removida para uma nova vila, os conflitos se instalaram, considerando-se inclusive os valores subjetivo e objetivo que as pessoas atingidas atribuíam ao fato 
de pertencerem ao povoado e ao rio que o banhava. Houve, na verdade, uma quebra no tecido social que dava sustentação à existência daquela comunidade e, em decorrência, quebrou-se o sentido de pertencimento ao lugar, o qual funcionava como aporte identitário dos moradores locais. Esse processo distorce e altera a percepção sobre o lugar que ora lhes é destinado, pois se antes o "seu" lugar era visto como aquele que cria vida, dá vida e reproduz os sentidos sociais da comunidade-que organizaram o cotidiano-, a partir de agora esse outro lugar ganha nova perspectiva, podendo surgir inclusive como ameaçador. Assim:

O deslocamento ou a remoção desses grupos significa, frequentemente, não apenas a perda de terra, mas uma verdadeira desterritorialização, pois muitas vezes a nova localização, com condições físicas diferentes, não permite a retomada dos modos de vida nos locais de origem, sem contar o desmoronamento da memória e da identidade centrado nos lugares (Zhouri \& Laschefski, 2010, p. 25).

A inundação não somente implicou perdas das referências históricas, como também, e para agravar ainda mais, a terra prometida por eles alcançada não apresentava as mesmas condições que a anterior. Uma vez que organizavam suas vidas em torno do rio, este era percebido como uma dádiva da natureza, algo perene, com o qual estabeleceram uma relação de dependência, posto que representava sua fonte de sobrevivência; a pesca e a produção agrícola eram promissoras. O rio era fonte de vida, bem como um elemento presente e reverenciado nas manifestações culturais e religiosas do povoado.

Os moradores foram surpreendidos no meio da noite pela invasão das águas, cuja natureza da intensidade desse momento é refletida por um morador e traduz bem o sentimento do grupo: "[...] a gente não teve como correr, não teve pra onde sair, num instante bateu nós [...]" (Entrevistado 4). Isto demonstra em sua medida o grau das marcas profundas que o desastre ambiental provocou nessas pessoas, alterando sobremaneira seus respectivos cotidianos pelo resto da vida, que se interpõe no social criando, por sua vez, um discurso que perdura no tempo desde o momento do sinistro, fazendo com que revivam, na atualidade, a memória do processo de destruição e êxodo, mesmo nos mais jovens habitantes. Nesse momento, os moradores do Cabeço, imbuídos de estímulos externos, iniciam o processo de ressignificação da nova realidade, reconfigurando suas percepções diante do desastre que os vitimou, com perdas afetivas e sociais.

A Entrevistada 6, natural do Cabeço, foi obrigada a deixá-lo para trás e, junto com ele, a sua história ali vivida, isto há quatorze anos, implicando perdas afetivas irrecuperáveis. Remete a essa experiência de perda com arranjos cognitivos que ela realiza para explicar a si mesma sua atual condição de vida, nos quais privilegia o argumento religioso. Esse argumento diminui suas tensões, adota uma atitude que denota aceitação dos acontecimentos ao dizer que "Deus quis. Ele deu e Ele mesmo tirou", estabelecendo assim uma ligação mítica entre as dimensões tangível e intangível da vida do homem na terra, causada pela invasão das águas que fez desaparecer seu povoado de origem, a partir do qual construiu as bases afetivas de seu sentimento de pertencimento ao mundo e a um determinado grupo social. O seu povoado continha suas memórias, ou seja, a sua história de vida.

Esta relação mítica entre o homem e a natureza aparece na fala de outros moradores. Eles descrevem a inundação do povoado como uma relação divina entre o homem e a natureza, pois "é coisa de Deus", isentando o homem de responsabilidade sobre seu destino, sobre sua felicidade ou infortúnio. E, na medida em que se intensifica esta 
mediação, vemos que o Cabeço aparece em suas respectivas falas como um lugar também divino, portanto, idealizado à semelhança de um paraíso, onde imperava certa perfeição, seja da natureza, seja das relações entre os homens, afinal viviam apartados de um mundo impuro, possivelmente abandonado por Deus.

Quando se diz que a redução da vazão é decorrência da barragem, tem-se uma visão mais crítica da realidade, havendo indícios de compreensão de uma natureza enquanto um espaço determinado e percebido no tempo, resultado das relações entre os grupos sociais e o meio natural, em que a natureza estaria a serviço do homem no atendimento de suas necessidades numa concepção predatória. Mas, a natureza ainda é tomada pelo sentido de ser uma “coisa de Deus", como se somente assim pudesse estar assegurada sua inviolabilidade. Como se a solução estivesse nesse argumento de ser algo de Deus, portanto, seria profano modificar seu curso.

Quando o Entrevistado 4, morador, descreve a catástrofe como consequência das obras das barragens no rio São Francisco, é interessante notar que parece haver alguma dificuldade em mencionar, mais objetivamente falando, a quem responsabilizar pela construção da barragem e pela inundação do Cabeço, de forma que quando o morador trata do assunto, o sujeito aparece oculto através do uso do verbo na terceira pessoa - "Disse que" ou "Foi por causa que fizeram uma barragem". A inundação ocorreu de forma abrupta durante a noite. Seu patrimônio foi perdido.

Em novo território, os moradores perdem sua identidade com o lugar de antes, têm que ressignificar os velhos hábitos e costumes, produzindo laços sociais, submeter-se por vezes às novas normas de conduta, enfim, reinventar a velha em uma nova vida e reinventar a si próprios, pois saíram de uma condição de autóctone para uma condição de es- trangeiro. Desterritorializados, passam a encontrar dificuldades de adaptação no seu novo lar, perdem a sua trama social, perdem a capacidade do fazer.

Ao deixar sua terra natal, quebram-se as ligaduras que amalgamam as redes e tecidos de relações sociais que legitimam e garantem os hábitos, os costumes, os princípios e as normas de conduta. No dizer de Souza (2007, p. 126), "alteram o substrato do tecido relacional que confere sustentabilidade aos hábitos". Os moradores saíram de um lugar tranquilo, em que as pessoas viviam como irmãos, "lugar era tranquilo [...] eram uns irmãos" (Entrevistada 6).

A Entrevistada 1, moradora, afirma que " $O$ mar comeu, tirou a gente de lá. Só sabe é Jesus Cristo. Só Deus sabe. Foi o destino do mar que invadiu". Mais uma vez, aparece a relação mítica do homem com a natureza no sentido de que a natureza é generosa e farta, pois, por intermédio dela, lhe era possível sobreviver e experimentar outras formas de prazer, como as festas e o contato com o mundo lá fora, uma vez que o povoado atraía muita gente, inclusive de outros países. Dessa forma, homem e natureza, mediados por um pensamento mítico, mantêm essa relação de simbiose ou mesmo de troca.

Para além das perdas materiais, o que se observa, por excelência, são as perdas subjetivas. O que se colocou para essa pequena comunidade de pescadores, com uma força absoluta, foi o sentimento de desamparo diante de um querer divino, pois foi “Deus que quis”, que os desalojou não só do seu povoado como também de um modo de vida que, em suas idealizações, se aproximava da vida em um paraíso onde, diante de uma natureza não violada pelo homem, predominava a fartura da água, da pesca, bem como a comunhão ou a solidariedade entre os moradores. 
O Entrevistado 8 tinha sua vida organizada em torno da pescaria, à semelhança dos demais moradores, sendo esta atividade a sua única fonte de renda. Sobre a inundação, ele diz que foi provocada "pela falta de água no rio, que não estava enchendo como antigamente", dando margem à inundação das águas do mar. O processo foi lento, "foi aos pouquinhos, mas não levou muito tempo para invadir o Cabeço [...]. Foi devagarzinho". Ele estabelece uma relação entre a inundação e a construção da barragem, contudo, não abordou claramente, não se apontou um responsável direto pela questão ambiental e social provocada pelas barragens no rio.

Também o Entrevistado 7, morador, sustenta que a inundação do Cabeço se deu por conta da construção de barragens que artificializaram a vazão e fizeram o rio perder a força diante do mar. "Faltou água do rio através das barragens que foi feito, porque chuva tem. Agora as barragens que foi feita, o rio artificial".

A análise dos moradores não se volta apenas para suas perdas subjetivas, mas perda de uma peculiar relação com o rio, sustentada por suas representações que o apresentam como fonte de vida, não só por sua intensa participação nas atividades econômicas ou pelo sentido da exuberância ou prodigalidade, mas pelo que foi sinalizado por uma moradora, cuja narrativa pode ser tomada como metáfora ilustrativa da ideia de um rio associado à vida, visto por meio de suas lembranças que preservam os acontecimentos que a transformaram na parteira do povoado:

Comecei a fazer o parto com 11 anos de idade, quando minha mãe mandou eu pegar água no rio, foi quando eu encontrei uma lavadeira na beira do rio em trabalho de parto, e tive que ajudá-la a parir, tirando a criança, cortando o cordão do umbigo. Tempos depois, aprendi com Dr. Hélio, parteiro no Hospital em Penedo. Fiz um estágio de três meses, no lugar de uma prima, que estava de licença. É dai que já vem o dote. Quando cheguei no Cabeço, tinha delas que paria nas canoas. A qualquer hora fazia o toque, quando o parto era meu, eu fazia, quando era cesárea, eu acompanhava até a maternidade. O prefeito deu o trabalho pela prefeitura, concursado, com portaria (Entrevistada 5).

$\mathrm{Na}$ beira do rio, ela assistiu ao nascimento de uma vida e tomou para si esse ofício que, posteriormente, após anos de prática, teve o reconhecimento e registro legal pela prefeitura do município de Brejo Grande/SE. Ao compreender que suas vidas se alteraram em função das intervenções ocorridas no rio, os moradores percebem sua ligação intrínseca com o meio ambiente, mais especialmente com o rio. Eles intuem essa ligação compreendendo sua existência e sua relação de dependência ambiental própria ao modo de produção criado em função dessa mesma base material. Percebem que houve uma perda das suas referências culturais e simbólicas, bem como das redes de parentesco estabelecidas naquele espaço e que a memória coletiva assentada vai se transformando de forma exaustiva num ontem.

Os moradores buscam no passado suas identidades e ao mesmo tempo constroem novas identidades. Essa reconstrução de nova identidade, dialética entre passado e presente, se deu a partir da inundação do Cabeço, de forma que estabeleceu um antes e um depois, fragmentando as identidades existentes e impondo uma nova dinâmica a eles, forçando-os a ressignificarem suas vidas e reconstruir novas identidades.

A memória do desastre reforça a sua identidade de morador do Cabeço que pescava, plantava e colhia arroz e tirava coco, uma vida comum de ribeirinho do rio São Francisco, mas específica de uma ilha na foz. Uns tendem a homogeneizarem-se com os novos hábitos, outros resistem, reafirmam as suas identidades crivadas de um passado que 
remonta à fartura do antes, quando ainda existia o Cabeço e desenvolviam seu modo de produção e construíam sua base material e imaterial.

Eles foram obrigados a uma reorganização interna de sua existência, uma reelaboração de novas práticas sociais, antes mediadas pelo ambiente naturalmente circunscrito ao rio, uma vez que se instaurou uma nova ordem social que exigiu dos mesmos um grande poder de adaptação. Para dar conta dessa exigência, a população necessita fazer uso de três estratégias que mantêm entre si uma relação de dependência. Trata-se de desenvolver conhecimento acerca dos problemas ambientais, das práticas sociais e da diversidade de alternativas existentes, as quais permitirão uma escolha da que seria adequada para solucionar os problemas ambientais (Jacobi, 2006, p. 30).

Jacobi (2006, p. 28) verifica que as mudanças no meio ambiente criam percepções que são resultantes dos impactos objetivos das condições reais, da intervenção social e dos valores culturais que agem na vivência destes impactos sobre os indivíduos. Esse fenômeno se encontra na fala do Entrevistado 7 , morador, ao afirmar que o surgimento da ilha é importante para os pescadores, na medida em que contribui para acompanhar o tempo da maré, se constituindo em um fator positivo para a pesca.

O Entrevistado 9, pescador, refere-se ao seu modo de se relacionar com a natureza, ao afirmar que: "'meu tempo é o tempo da maré, não tenho hora pra sair e nem pra voltar". Isso permite apreender que a relação do homem daquele povoado com o meio ambiente natural, transcrito na fala deste pescador, demonstra a relação intrínseca entre homem e natureza, como também de conhecimento do seu fazer, do seu modo de produção e da construção cultural. A sua expressão ultrapassa o sentido monolítico do tempo, o qual se apresenta, para o pescador, em movimento, em consonância com o fluxo das marés. Esta, uma estratégia de observar o tempo, depois de sua dimensão eterna, trazendo-o para um presente que se esvai rapidamente, com o vai e vem da maré, é, também, uma forma de regular o tempo e o diálogo com a natureza, ou seja, a natureza determina o tempo de ir e vir para o mar, da qual a realização da pesca é a dialética entre o ser e a natureza. Esta dimensão de tempo remonta à reflexão de tempos múltiplos de Santos (2006), para o qual o tempo linear não é a única concepção de tempo no mundo.

\section{Conclusões}

A apropriação dos recursos hídricos pelo setor elétrico, com prioridades para a geração de energia, na bacia hidrográfica do São Francisco, tem causado impactos socioambientais, principalmente no tocante à redução das vazões interanuais do rio.

Estas intervenções no rio São Francisco se fizeram sentir tanto no ambiente biofísico quanto no social, o que levou à extinção do Povoado Cabeço/SE. Os impactos ambientais imprimiram modificações irreversíveis na paisagem natural e no ciclo de vida do rio, após a construção, instalação e operação da hidrelétrica do Xingó. Estes impactos têm ameaçado de extinção a flora, a fauna e o próprio rio, ao mesmo tempo em que inviabilizaram as condições de moradia e sobrevivência da comunidade do Cabeço/SE.

Aparentemente em nome do bem-estar social, ao efetivar seus processos, a hidrelétrica de Xingó coloca em sofrimento o humano e a natureza daquele contexto específico e de outros indiretamente correlacionados, a partir da supressão de realidades subjetivas e da degradação profunda da natureza, impondo novo modo de vida e convivência com o ambiente natural, já submetido a toda forma 
de controle e de exploração, como se não fizesse parte da sociedade, revelando assim uma relação de alienação entre os dois polos citados - homem e sociedade.

Se num primeiro momento os moradores respeitavam os ciclos do rio, a sua potência enquanto causa de vida, por se perceberem fazendo parte de um ecossistema no qual eles tinham um lugar bem delimitado, muito embora utilizando processos tradicionais na agricultura e na pesca artesanal, isso não foi levado em conta durante as intervenções da hidrelétrica, na região do Cabeço, não restabelecendo, portanto, o status quo dos grupos atingidos como produtores de sua economia ao retirar-lhes a sua base material de produção e que lhes dava certa autonomia diante da relação capital/trabalho.

Além dos aspectos mais voltados para o ambiente como espaço físico, unicamente, se é que se pode fazer essa separação, tem-se a degradação de um modo de vida, com enfraquecimento dos laços sociais e perda de referências no mundo, exigindo das pessoas, sobretudo dos mais velhos, um esforço

\section{Referências}

Acselrad, H.; Da Silva, M. das G. Rearticulação social de terra e trabalho em áreas de grandes projetos hidrelétricos na Amazônia - o caso de Tucuruí. In: Zhouri, A. (Org.). As tensões do lugar:hidrelétricas, sujeitos e licenciamento ambiental. Belo Horizonte: Editora UFMG, 2011. p. 61-92.

Aguiar Netto, A. de O.; Lucas, A. A. T.; Santos, A. G. C.; Almeida, C. A. P de. Água e ambiente no baixo São Francisco sergipano. In: Lucas, A. A. T.; Aguiar Netto, A. de O. (Orgs.). Águas do São Francisco. São Cristóvão, SE: Edufs, 2011. p. 15-32.

Araújo, S. S. de; Lima, L. Mapa de localização do povoado Cabeço/Brejo Grande/SE. São Cristóvão, SE. 2014.

ANA - Agência Nacional de Águas. Ministério do Meio Ambiente. Monitoramento Hidrológico no Setor Elétrico. de produção de novos sentidos para conectá-los com o mundo ou com sua nova vida.

No caso do Povoado Cabeço/Brejo Grande-SE, foram alteradas as práticas sociais, o uso do território, dos recursos e as representações sociais dos beiradeiros. A regularização da vazão do rio modificou a percepção dessa população, uma vez que sempre viram as inundações naturais como positivas, tanto para a pesca quanto para a agricultura. Também reconfigurou a realidade dos moradores, afetando inclusive a memória coletiva, em torno da qual organizam (organizaram) suas vidas no tocante às relações socioafetivas e ao esforço de sobrevivência.

$\mathrm{O}$ modo como esses moradores percebem o meio ambiente e representam o cotidiano se encontra no âmbito do intangível e do tangível, na medida em que a compreensão que essas modificações se deram se encontra tanto como obra divina, de um ente supremo, quanto como obra do homem, como ser subordinado, caracterizando essa ligação mítica entre as obras de Deus e do homem.

Disponível em: < http://www2.ana.gov.br/Paginas/servi$\cos$ /informacoeshidrologicas/monitoramentohidro.aspx $>$. Acesso em: ago. 2014.

Bardin, L. Análise de conteúdo. Lisboa, Portugal: Editora 70,2006 .

Barros-Platiau, A. F.; Sayago, D. A. V.; Nascimento, E. P.; Mota, J. A.; Drummond, J. A.; Mourão, L.; Duarte, L. M. G.; Wehrmann, E. de S. F.; Bursztin, M.; Bursztin, M. A.; Little, P. E.; Theodoro, S. H. Uma crise anunciada. In: Theodoro, S. H. Mediação de conflitos socioambientais. Rio de Janeiro, RJ: Garamond, 2005. p. 23-71.

Bourdieu, P. Esboço de uma teoria da prática. In: Bourdieu, P. Sociologia. São Paulo: Ática, 1983. p. 46-81. 
CHESF - Companhia Hidrelétrica do São Francisco. Ministério das Minas e Energia. Dados de vazão. 2006.

Del Rio, V.; Oliveira, L. Cidade da mente, cidade real: percepção ambiental e revitalização na área portuária do RJ. In: Del Rio, V.; Oliveira, L. (Orgs.). Percepção ambiental: a experiência brasileira. São Paulo, SP: Studio Nobel/ UFScar, 1996. p. 3-22.

Ferrara, L. d'A. Olhar periférico: informação, linguagem, percepção ambiental. São Paulo, SP: Edusp, 1993.

Fontes, L. C. da S. O Rio São Francisco após as Grandes Barragens - mudanças recentes no regime hidrossedimentológico e na dinâmica fluvial do baixo curso. In: Lucas, A. A. T.; Aguiar Netto, A. de O. (Orgs.). Águas do São Francisco. São Cristóvão, SE: Edufs, 2011. p. 33-68.

Holanda, F. S. R.; Santos, C. M. dos; Casado, A. P. B.; Bandeira, A. A.; Oliveira, V. S. de; Fontes, L. C. da S.; Rocha, I. P. da; Araújo Filho, R. N. de; Góis, S. S.; Vieira, T. R. S. Análise multitemporal e caracterização dos processos erosivos no baixo São Francisco sergipano. Revista Brasileira de Geomorfologia, 8(2), 87-96, 2007. Disponível em: <http:// www.ugb.org.br/home/artigos/RBG_8_2/RGB_SF08.pdf>.

IBGE - Instituto Brasileiro de Geografia e Estatística. Cidades do Brasil, 2014. Disponível em: $<$ http://www.cidades. ibge.gov.br/xtras/home.php?lang=>.

Jacobi, P. Cidade e meio ambiente: percepções e práticas em São Paulo. 2. ed. São Paulo: Annablume,2006.

Jesus, N. B. de; Gomes, L. J. Conflitos socioambientais no extrativismo da Aroeira (Schinus terebenthifolius Raddi), Baixo São Francisco - Sergipe/Alagoas. Ambiente \& Sociedade, 15(3), 55-73, 2012. DOI: 10.1590/S1414-753 X2012000300005

Latour, B. Jamais fomos modernos: ensaio de antropologia simétrica. 2. ed. Rio de Janeiro: Editora 34, 2011.

Marconi, M. de A.; Lakatos, E. M. Metodologia científica. 4. ed. São Paulo: Atlas, 2010.

Medeiros, P. R. P.; Knoppers, B. A.; Santos Junior, R. C. dos; Souza, W.F.L. de. Aporte fluvial e dispersão de matéria particulada em suspensão na zona costeira do rio São Francisco (SE/AL). Geochimica Brasiliensis, 21(2), 212-231, 2007. Disponível em: $<$ http://www.institutomilenioestuarios.com. br/pdfs/Produtos/022/22_Medeirosetal2007.pdf >.
Nascimento, E. P. do. Os conflitos na sociedade moderna: uma introdução conceitual. In: Bursztin, M. (Org.). A difícil sustentabilidade: política energética e conflitos ambientais. Rio de Janeiro, RJ: Garamond, 2001. p. 85-106.

Oliveira, A. M.; Santos Junior, R. C. dos; Hernandez, A. de O.; Segundo, G. H. C.; Araújo, A. E. de M. A morte do delta do rio São Francisco. In: Anais do II Congresso sobre Planejamento das Zonas Costeiras dos Países de Expressão Portuguesa; IX Congresso da Associação Brasileira de Estudos do Quaternário; II Congresso do Quaternário dos Países de Língua Ibérica. Recife: ABEQUA, 2003. Disponível em: <http://www.abequa.org.br/trabalhos/ dinamica_costeira_294.pdf $>$.

Reigota, M. Meio ambiente e representação social. 6. ed. São Paulo: Cortez, 2004.

Santaella, L. Percepção: fenomenologia, ecologia, semiótica. São Paulo: Cengage Learning, 2012.

Santos, B. de S. Conhecimento prudente para uma vida decente. São Paulo: Cortez, 2006.

Sergipe. Secretaria de Estado do Planejamento e da Ciência e Tecnologia. Relatório Técnico $n^{\circ}$ 01/97 - Comitê Coordenador do Plano Estadual de Recursos Hídricos: Ref: ao processo erosivo na foz do rio São Francisco. Aracaju: CPERH, Jul. 1997.

Silva, T. T. da. A produção social da identidade e da diferença. In: Silva, T. T. da (Org.). Identidade e diferença: a perspectiva dos estudos culturais. 4. ed. Petrópolis: Vozes, 2005. p. 73-102.

Souza, M. R. M. de; Neumann Leitão, S. Consequências socioeconômicas dos impactos antrópicos no estuário do rio São Francisco em Brejo Grande, Sergipe-Brasil. Trabalho Oceanográfico, 28(1), 97-116, 2000. Disponível em: $<$ http://www.ufpe.br/tropicaloceanography/artigos_completos_resumos_t_d/28_2000_2_souza.pdfs.

Souza, R. M. Redes de monitoramento socioambiental e tramas da sustentabilidade. São Paulo: Annablume, 2007.

Souza, W. F. L. de; Medeiros, P. R. P.; Brandini, N.; Knoppers, B. Impactos de barragens sobre os fluxos de materiais na interface continente-oceano. Revista Virtual Química, 3(2), 116-128, 2011. Disponível em: <http://www.uff.br/ RVQ/index.php/rvq/article/viewFile/144/171>. 
Spink, M. J. O estudo empírico das representações sociais. In: Spink, M. J. (Org.). O conhecimento do cotidiano: as representações sociais na perspectiva da psicologia social. São Paulo: Brasiliense, 2004. p. 85-108.

Triviños, A. N. S. Introdução à pesquisa em ciências sociais. 5. ed. São Paulo: Atlas, 2009.

Vargas, M. A. M. Desenvolvimento regional em questão: o baixo São Francisco revisitado. São Cristóvão/SE: UFS, NPGEO, 1999.

Woodward, K. Identidade e diferença: uma introdução teórica e conceitual. In: Silva, T. T. da (Org.). Identidade e diferença: a perspectiva dos estudos culturais. 4. ed. Petrópolis: Vozes, 2005. p. 7-72.

Zhouri, A.; Laschefski, K. Desenvolvimento e conflitos ambientais: um novo campo de investigação. In: Zhouri, A.; Laschefski, K. (Orgs). Desenvolvimento e conflitos ambientais. Belo Horizonte: Editora UFMG, 2010. p. 11-31.

Zhouri, A.; Oliveira, R. Paisagens industriais e desterritorialização de populações locais: conflitos socioambientais em projetos hidrelétricos. In: Zhouri, A.; Laschefski, K.; Pereira, D. B. A insustentável leveza da política ambiental: desenvolvimento e conflitos socioambientais. Belo Horizonte: Autêntica, p. 49-64, 2005. 